\title{
Bridging the Mental Health RTI Theory to Practice Gap: Preliminary Investigation into Current Practices, Facilitators and Barriers
}

\author{
Denise R. Foley \\ Worcester State University, United States of America
}

\begin{abstract}
Twenty-plus percent ( 8 to 12 million) of US school-age youth have moderate to severe emotional, behavioral and mental health problems. Eighty percent receive no mental health services. For the few who do receive it, the vast majority of mental health services are school-based. National- and state-level initiatives and the literature regarding mental health RTI practices provide conceptual frameworks but lack research-based guidelines for schools to implement and evaluate interventions or monitor progress. This study sought to begin bridging the theory to practice gap for best practice guidelines and procedures for providing tiered systems of school-based mental health supports for children and adolescents by identifying baseline current practices, facilitators and barriers. Preliminary results of a state-wide survey of 174 psychologists found that only 16\% of schools engaged in universal mental health screening. Generally, data regarding risk or documented mental health concerns was not systematically gathered or maintained for students not services or accommodations for mental health concerns via IEPs or 504 plans. Facilitators and barriers to mental health RTI centered on available resources to support students, communication, expertise and leadership. Next step recommendations for data collection, analysis and monitoring, and regulation-compliant communication processes are offered.
\end{abstract}

\section{Introduction}

One-in-five (8 to 12 million) school-aged children and adolescents in the United States (US) have moderate to severe emotional, behavioral and mental health (mental health) problems [1]. Suicide is the second leading cause of death among adolescents ages 15-19 and third among 10-14 year-olds [2] Depression, the most substantial risk factor for suicide, has increased almost forty-percent in children and adolescents since 2005 [3]. These statistics are made even more alarming by the fact as many as eighty percent of school-aged youth with mental health disorders do not receive any mental health services [4]. Columbine. Aurora. Sandy Hook. Sadly, on almost a daily basis we are all-to-often reminded of the tragic consequences of untreated and unmonitored mental health problems that begin in childhood and adolescence.

Of the small percentage of youth who do receive mental health services, the vast majority do so in public schools [4]. Both children and adolescents report a marked preference for school-based over community-based mental health services [5]. For youth receiving community-based services, additional schoolbased supports are considered essential for longterm well-being [6]. Though schools are considered to be the best, most natural settings to begin to combat the mental health crisis in school-aged children and adolescents through prevention and treatment [4], there is surprisingly little research-based direction on how to do so.

This paper describes the initial results of a study designed to begin to address the literature gap around best practice guidelines and procedures for providing tiered systems of school-based supports to meet the mental health needs of children and adolescents. Seemingly unique in the literature relative to its focus and scope, the overarching goals of the study were to: 1) Identify facilitators and barriers to systematic screening, providing and evaluating effective interventions, and monitoring mental health progress and outcomes; and 2) Identify efficient, regulation-compliant procedures to collect, analyze, track and communicate data related to mental health concerns, progress and outcomes across time (i.e., during and across academic years) and settings (e.g., among grades \& schools). 
A number of topics were explored in this study, this paper focused on the questions designed to determine current practices. In a problem-solving model, this would be establishing "baseline." The questions were: 1) How are students at-risk for mental health problems identified? 2) What data is collected? 3) What tools are used? 4) Regarding students who do not receive services and/or accommodations for mental health problems though an IEP or 504 plan, how do school-based professionals monitor their mental health progress over time? 5) What facilitators and barriers to mental health RTI do these current practices suggest?

These questions were asked of school psychologists, personnel not only trained to but also most likely to participate in all phases of school-based mental health: from design and implementation to evaluation [4].

\section{Literature Review}

Across and within disciplines, various "umbrella" terms are used for social, emotional, behavioral, and mental health problems. Reflecting the regional vocabulary, the term "mental health" was used in this study to the range of "non-academic" problems that children and adolescents present with at school.

The crisis in youth mental health has resulted in both federal and state initiatives that make addressing these concerns in schoolsettings a priority. For example, the federal Affordable Care Act of 2010, provided millions of dollars in competitive grants to improve and expand the services provided through the School-Based Health Centers. Similarly, in Massachusetts, where this study took place, the 2008 Act Relative to Children's Mental Health required the creation of the Task Force on Behavioral Health and Public Schools. The Task Force was charged with creating a framework for schools and communities to design and implement local organizational changes to create safe and supportive school environments, especially for students with mental health concerns and behavioral challenges [8].

Multiple professional educational organizations across the country have, individually or collaboratively [9], put forth frameworks provided mental health prevention and intervention services in school settings. In this same vein, during academic year 2010-11, the Division of Special Education within the Massachusetts Department of Secondary and Elementary Education (DESE) developed a "blueprint" entitled, the "Massachusetts Tiered System of Supports." Since its unveiling, support documents have been released in recent years, (e.g., explaining the principles and a selfassessment tool) to encourage schools and districts to make systemic changes at the classroom-, school- and district-levels to meet both the academic and social-emotional and behavioral needs of all students, including those with disabilities, whose first language is not English and those who are academically advanced [7].

What these initiatives provide are conceptual frameworks for prioritizing student mental health concerns and providing services within school settings. What they lack, however, are research-based guidelines on how to implement and evaluate intervention effectiveness and how to monitor and communicate about students' mental health progress.

Multi-Tiered Systems of Supports (MTSS) is an umbrella term used to describe schoolbased service delivery in which students receive a continuum of effective, research-based socialemotional and academic supports, instruction and interventions [10]. MTSS is typically divided along the two broad domains of academic progress and social-emotional, mental and behavioral functioning and described by the terms Response to Intervention (RTI) and Positive Behavioral Support (PBS), respectively [11]. Though distinct, educators at all levels [12] and even leading researchers in the field [13] often use the terms RTI and MTSS interchangeable with RTI being the more recognized and employed term. Reflecting this backdrop, the broader conceptualization of the term RTI as encompassing both mental health and academic issues is employed herein.

The roots of RTI can be traced back more than two decades from the diverse research fields of applied behavior analysis and curriculum-based measurement, as well as, precision teaching and effective teaching [14]. Reflecting this rich heritage, there is no "one" way to "do" RTI. What RTI "looks like" at the local level is as unique as the schools and districts in which they are conceived, developed and implemented. That said, there are core RTI principles. As articulated by Barnes and Harlacher [15] these include: 1) a systems-level mindset, 2) proactive and preventative methods, 3) a problem-solving orientation, 4) researchbased, effective practices, and 5) data-based decision-making.

These principles reflect the ultimate goal of 
all RTI models: to identify and provide appropriate support to all students, when they need it through general education processes. As such, RTI counters a traditional, reactive approach to intervention, generally referred to as a "wait to fail" model where the focus on is individual struggling students, "special" labeling (i.e., special education eligibility) is required before interventions are provided and many students with critical needs "slip through the cracks" without any assistance [14].

Almost all RTI models are visually represented in the form of a triangle or pyramid comprised of several (typically three) layers. As illustrated in Figure 1, these layers highlight a key feature of all RTI models: "tiers" of intervention. Tier 1 includes a sound, general curriculum and school-wide behavioral policies which are effective for $85-90 \%$ of students. Tier 2 includes targeted interventions for the $10-15 \%$ of students who are at-risk for academic or mental health difficulties. Service delivery is typically in small groups. Tier 3 interventions are for the $1-5 \%$ of students requiring intensive, individual academic and social-emotional and behavioral supports.

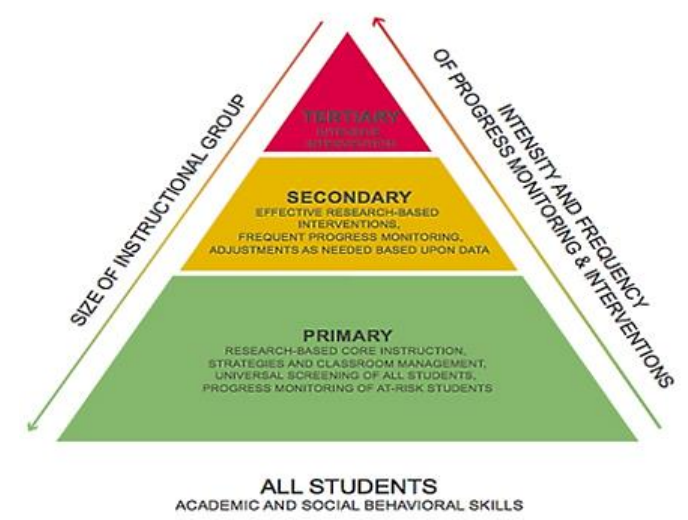

Figure 1. Common Model of RTI Processes Image from http://firstyearschoolpsych.blogspot.com

As mentioned above [15] an essential element of any RTI model is data-based making. These are based on ongoing assessment: from universal screening of all students to frequent progress monitoring of students requiring targeted (Tier 2) or intensive (Tier 3) services [14].

With RTI, students can "occupy” more than one tier at any given time. For example, an individual student may be on tier 1 for reading, tier 2 for behavior, and tier 3 for mathematics. The "higher" the tier, the more intense the service(s) and the more frequent the assessment(s). Student "movement" among tiers is data-driven.

Though widely-adopted in parts of the United States for more than two decades, especially in the Midwestern and Central states [14], it has only been since the reauthorization 2004 Individuals with Disabilities Act, the federal law concerning the education of students with disabilities, that the concept of RTI gained more attention across the country [13]. The legislative and education initiatives mentioned above highlight how concerted efforts to moving schools towards academic and mental health RTI have only begun to gain traction in the past five to six years in Massachusetts.

Though RTI is meant to extend across and beyond the academic curriculum and across grade levels, the vast majority of research has focused on remediating reading difficulties, with an emphasis on improving early basic skills, typically oral reading fluency (speed + accuracy) [16]. Though differential levels of support and data-based decision-making processes is conceptually extended to mental and behavioral health of school aged children [9, 13], the literature on RTI for mental and behavioral supports is scant and generally limited to calls for or investigations of screening. For example, a recent estimate of $13 \%$ of schools engaging in social-emotional screening practices was considered preliminary [17].

Unlike the extensive literature on academic progress, the mental health RTI literature is generally limited to descriptions of suggested elements for Tier 1, 2 and 3 interventions. Similarly, there are no established, agreed-upon guidelines on how to progress monitor Tier 1, Tier 2 or Tier 3 mental and behavioral health interventions in schools [18]. Also, there are no guidelines on how to determine "responsiveness" to these interventions [19]. Thus, mirroring federal and state legislative mandates and initiatives, the literature on mental health RTI provides many recommendations for what to do, but no guidelines for how to do it.

For some, the term "record keeping" might conjure notions of basic or mundane routines and procedures. However, in schools, especially as relates to mental health concerns, record keeping is anything but simple. As revealed across a number of forums, from listserv discussion threads to commissioned reports [8]: educators, including school-based mental health practitioners, have many questions and frequently ask for guidance. Responses from state and national professional organizations relative to recording keeping are consistent in 
their generality. Educators are typically advised to: 1) act in accordance with the requirements of federal Family Educational Rights and Privacy Acts (FERPA) and 2) follow state law and local regulations while 3 ) exercising caution when using different technologies [20]. References to the American Psychological Standards on record keeping are also frequent [21].

In Massachusetts school personnel can access explicit regulations around the content, access to, storage and disposal of students' permanent and temporary (i.e., special education) records, as well as, guidance on the use of email and the personal memory-aiding notes [22]. However, as of this writing, there are no guidelines around the collection and maintenance of data that might be utilized in mental health RTI processes in Massachusetts schools.

\section{Methodology}

\subsection{Participants}

A message with a link to an electronic survey was sent to 456 full members of the Massachusetts School Psychologists Association (MSPA) via the organization's listserv. Though MSPA extends membership to affiliate professionals (e.g., speech and language therapists and special education teachers), as well as, those who are retired or in private practice, the survey targeted licensed school psychologist employed in public or private schools across Massachusetts. Of the two hundred nine surveys that were begun, 174 completed surveys were determined acceptable for inclusion in this study. Respondents were anonymous in that they did not provide any identifying information beyond the demographic variables summarized in Table 1.

\subsection{Measure}

Twenty-nine questions were developed and sent in an electronic format to field experts for feedback. These included five specialist-level and two-doctoral-level school-based K-12 practitioners and three professors of education with advanced training and expertise in school psychology and educational research. This process was completed prior to dissemination to the target population to ensure that survey questions that were not only easy to understand and reflected a range of typical responses, but also provided a balance of breadth and specificity to reflect the complexity of the mental health needs of school-aged students present with on a daily basis and capture the range of contemporary school-based mental health practices across the three-hundred plus school districts in Massachusetts.

Expert feedback on content, wording and format resulted in a reduced total number of questions, and a presentation manner that was easier to navigate and more efficient to complete. The final version of the survey was piloted with 10 field-based practitioners using the Qualtrics electronic survey platform. Their feedback resulted in several minor additional formatting changes.

The survey consisted of 25 total questions; however, not all respondents answered all questions. All respondents answered seven demographic questions (e.g., years of experience, and grade level(s) of students they typically work with). If respondents were assigned to more than one school in a district (common for school psychologists), they were asked to answer all subsequent questions with one school in mind. Four questions were asked about characteristics (e.g., public vs. private; geographic location) and diversity (e.g., racial, ethnic) of that school.

All respondents were asked if their school uses universal screening procedures for mental health problems. Only respondents answering "yes" to the question were then presented with two questions about frequency of screening and the tools employed. In addition to providing a list of suitable for and commonly used in schools to screen for mental health disorders, respondents were given options to delineate other tools and the frequency of administration if different from one to three times per year.

All respondents then answered the same 10 questions regarding: what other data is regularly utilized to identify students at-risk for or who demonstrate mental health problems; how concerns about students' mental health and progress are recorded, monitored and communicated; and which educator(s) are responsible for those functions. Three multi-part questions further investigated which (if any), and how mental health risk factors were documented, monitored and communicated across time and setting. In addition to established risk factors, for example, peer relationship difficulties, substance use and abuse, and family dysfunction or disruption [23], the option to articulate local risk factors was provided. Reflecting the documentation requirements outlined in regulations and anticipated differential answers, these blocks of 
questions were asked twice: once for with students receiving specially designed instruction and/or accommodations for mental health concerns via Individual Education Programs (IEPs) and 504 plans; and once for students who did not.

The final question was an open-ended request for comments regarding facilitators and barriers to mental health RTI in their settings, including key model features of systematic screening, providing and evaluating effective interventions, monitoring and communicating about students' mental health needs, progress and outcomes.

It should be noted that while all respondents were anonymous, in addition all elements that earned approval by the University's Human Subjects review Board (HSRB), in the invitation to take the survey, potential participants were notified that at the end of the survey, whether they completed it or not, they could self-identify (name, mailing address, preferred email and phone number) and choose to: 1) enter a drawing for one of 10 gift cards, each with a value of 50 US dollars; 2) indicate their interest in being contacted by the researcher for any reason including to discuss their current practices or to request more information; or 3) both. These three options were accessed via an unlinked Uniform Resource Locator (URL) generated by Qualtrics. Thus, anonymity was preserved.

\subsection{Analysis}

Before the data analysis, variables were examined for outliers and missing cells. Incomplete surveys and those completed by individuals other than licensed, practicing school psychologists were not included for analysis. Descriptive statistics were completed using data analysis tools available through the Qualtrics platform and the IBM Statistical Package for the Social Science (SPSS, V 23.0). Word-based analysis was used to identify themes in openended responses.

\section{Results}

Table 1 summarizes the demographic characteristics of the respondents, with special focus on one current school-based setting. The average number of years respondents had been employed as licensed school psychologists in public or private schools in Massachusetts and/or another state was just under 10 years $(\bar{x}=$ 9.7). However, in terms of total years, their range of experience varied widely: from less than one full year to thirty-seven years. More than half of respondents were early career professionals, with five or less years of experience.

In terms of the grade levels of students they worked with on a regular basis, almost $70 \%$ of respondents indicated early childhood and elementary school grades. Approximately the same percentage of respondents regularly worked in middle school (19\%) and high school $(19.7 \%)$ settings. Very few worked with students who are eligible for specially designed instruction until they turn 22 years old $(1.1 \%)$ or students of any age who receive specially designed instruction outside of a public-school district or collaborative $(0.7 \%)$.

Table 1. Demographics of Respondents $(n=174)$

\begin{tabular}{|c|c|c|}
\hline Variable & Number & Percentage \\
\hline \multicolumn{3}{|l|}{ Years of Experience } \\
\hline$<1$ & 24 & 13.8 \\
\hline 1 to 5 & 67 & 38.5 \\
\hline 6 to 10 & 21 & 12.1 \\
\hline 11 to 15 & 16 & 9.2 \\
\hline 16 to 20 & 14 & 8.0 \\
\hline 21 to 25 & 16 & 9.2 \\
\hline 26 to 30 & 10 & 5.7 \\
\hline 31-35 & 4 & 2.3 \\
\hline $36+$ & 2 & 1.1 \\
\hline \multicolumn{3}{|l|}{ School Level } \\
\hline PreK & 6 & 3.4 \\
\hline PreK-2 & 10 & 5.7 \\
\hline Elementary & 93 & 53.4 \\
\hline Combined & 2 & 1.1 \\
\hline \multicolumn{3}{|l|}{ Elementary-Middle } \\
\hline Middle & 20 & 11.5 \\
\hline Combined & 4 & 2.3 \\
\hline \multicolumn{3}{|l|}{ Middle-High School } \\
\hline High School & 39 & 22.4 \\
\hline \multicolumn{3}{|l|}{ School Type } \\
\hline Traditional Public & 170 & 97.7 \\
\hline Public Charter & 0 & 0 \\
\hline Private & 4 & 2.3 \\
\hline \multicolumn{3}{|l|}{ School Locale } \\
\hline Rural & 35 & 20.1 \\
\hline Suburban & 106 & 60.9 \\
\hline Urban & 33 & 19.0 \\
\hline \multicolumn{3}{|l|}{ School Diversity } \\
\hline More Diverse & 42 & 24.1 \\
\hline Similar & 27 & 15.5 \\
\hline Less Diverse & 105 & 60.3 \\
\hline
\end{tabular}

When asked to focus on a single school to discuss mental health RTI practices, as highlighted in, over half of respondents chose elementary schools. Approximately one-quarter 
of respondents chose to focus on high school, while the remainder was evenly divided between middle school and preschool settings. Several focused on schools with less typical grade configurations, i.e., spanning elementary through middle school grades or middle through high school grades. The vast majority, almost two-thirds of these schools, were classified as suburban. The remainder of the schools were evenly described as being in rural or urban locations. Almost all of schools were public as opposed to private schools.

Relative to the racial and ethnic diversity of the students in the schools, only $15.5 \%$ of respondents indicated that school reflected the diversity of students enrolled in Massachusetts public schools (63\% White; 19\% Hispanic; 9\% African-American/Black; 7\% Asian) while fourtimes that amount of respondents indicated that their schools were less diverse, i.e., lower percentages of one or more groups relative to students identified as White.

Though less than twenty percent of all respondents reported that their schools engaged in mental health screenings for all students, as reflected in Table 2, of those that did, over fifty percent did so two or more times annually.

Table 2. Percentage Conducting Universal Screening \& Frequency

\begin{tabular}{|c|c|c|}
\hline & Number & Percentage \\
\hline \multicolumn{3}{|l|}{ Universal Screening } \\
\hline No & 146 & 83.9 \\
\hline Yes & 28 & 16.1 \\
\hline \multicolumn{3}{|l|}{ Times per year } \\
\hline 1 & 9 & 32.1 \\
\hline 2 & 12 & 42.8 \\
\hline 3 & 2 & 7.1 \\
\hline Other & 5 & 17.9 \\
\hline
\end{tabular}

As summarized in Figure 2, schools engaging in universal screening generally did so using one or more published tools available as part of commercially packaged as RTI "systems" or "suites." From the list provided, respondents reported using: the Behavioral and Emotional Screening System (BESS), the Behavior Intervention Monitoring System (BIMAS), and Review360, Break Free from Depression (Break Free) and Signs of Suicide. The BESS, BIMAS and Review360 focus on mental health concerns. Break Free and SOS are curriculums available at no cost and include related screening tools. No respondents reported using the School Wide Information System
(SWIS), which may be used to track both academic and mental health data.

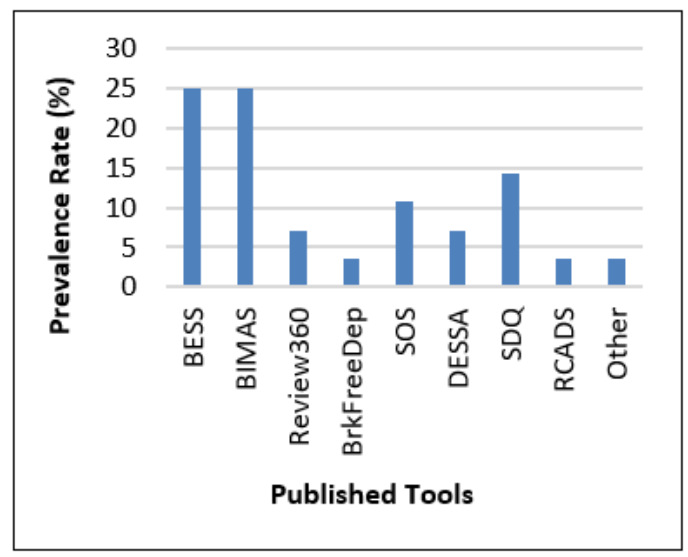

Figure 2. Published Tools Used in Universal Screening \& Monitoring

Besides the options provided, respondents indicated that they used other tools for mental health screening. These included the Strengths and Difficulties Questionnaire (SDQ) and the Revised Children's Anxiety and Depression Scale (RCADS), both of which are available online and free of charge. In addition, some respondents used the Devereux Student Strengths Assessment (DESSA) Tool, a rating scale that is available for purchase. One respondent reported that their school used a published tool but did not name it.

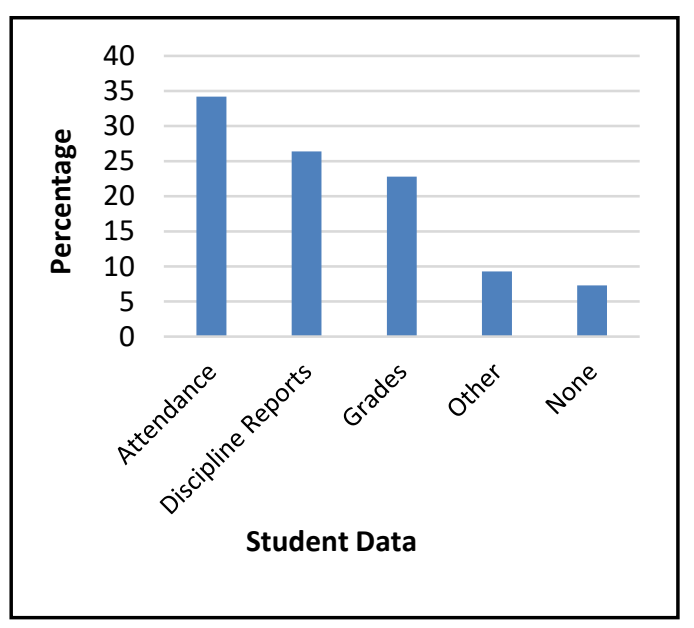

Figure 3. Other Data Used to Identify At-Risk Students

As highlighted in Figure 3, of the data readily available for all students, attendance (absent/tardy/early dismissal) was used by over one-third of schools to identify those at-risk for mental health problems. This was followed in 
roughly equal percentages (one-quarter), by disciplinary referrals and poor or declining grades. Just under ten percent of respondents reported that visits to the nurse's office and behavior tracking by individual teachers was also gathered to screen for potential mental health concerns. Almost the same amount of respondents indicated that no additional data was gathered.

Table 3. Recording Non-IEP or 504 Mental Health Concerns

\begin{tabular}{|c|c|c|}
\hline $\begin{array}{l}\text { Recording Method } \\
(\mathrm{n}=174)\end{array}$ & Number & Percentage \\
\hline Hardcopy & 19 & 10.9 \\
\hline Google Docs & 31 & 17.8 \\
\hline Other Electronic Means & 14 & 8.0 \\
\hline Varies & 29 & 16.7 \\
\hline \multicolumn{3}{|l|}{ Not Systematically } \\
\hline Recorded & 81 & 46.5 \\
\hline \multicolumn{3}{|l|}{$\begin{array}{l}\text { Personnel Responsible } \\
(n=153)\end{array}$} \\
\hline Mental Health Team & 79 & 51.6 \\
\hline Administrator & 2 & 1.3 \\
\hline Mental Health Individual & 65 & 42.5 \\
\hline Teacher & 7 & 4.2 \\
\hline
\end{tabular}

Respondents' characterizations of how the potential or demonstrated problems of students who do not receive services or accommodations specifically for mental health concerns (via IEPs or 504 plans) previewed their open-ended responses regarding the (mostly) barriers and facilitators regarding mental health RTI. Almost half of respondents indicated that, to their knowledge, any concerns about the mental health of their students (who did not receive services or accommodations specifically for mental health concerns), was not systematically recorded. One-quarter of respondents recorded the concerns electronically through limited access electronic means, e.g., google docs, the local data management system. Roughly ten percent recorded the concerns in hard copy (paper) format like a notebook or three-ring binder. Almost twenty percent reported that concerns about students' mental health were recorded but not in a consistent or centralized matter: recording varied with different grade levels or teams. Half of respondents indicated that individuals were responsible for recording and monitoring students' mental health over time.

Participants provided 316 discrete responses to the open-ended question regarding facilitators and barriers to Mental Health RTI. Figure 4 summarizes the most common themes identified by respondents in order. These were: available resources to support students, communication, expertise and leadership. These factors were categorizes as facilitators or inhibitors depending on where they fell on several continua which may described as: abundant to absent; systematic to idiosyncratic; consistent versus variable; and comprehensive to undeveloped. Available resources included funding, tools and human capital. Comments regarding communication generally referred to those among personnel (administration, faculty, mental health, other support staff) in one school or among settings, however, some respondents mentioned parents. Comments regarding leadership referred top-down versus grassroots perceptions of the need for mental health RTI, tacit or explicit support through actions and words, and ownership through roles and responsibilities. Training and expertise comments ranged from data-analysis and interpretation to providing preventative services and direct interventions

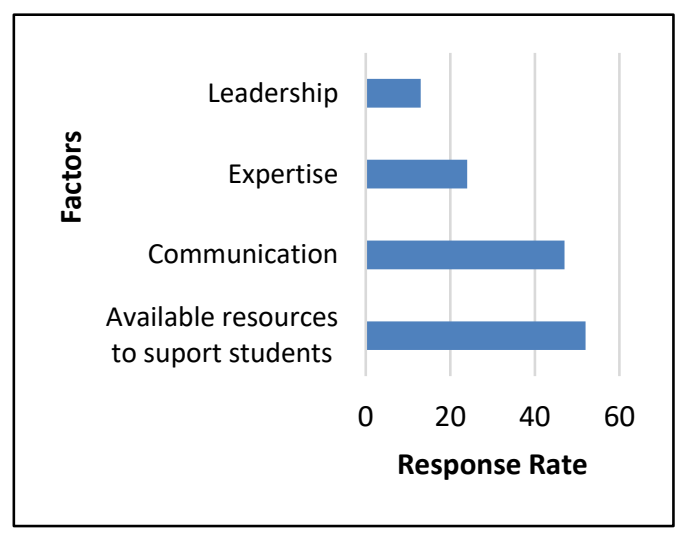

Figure 4. Facilitators and Barriers to Mental Health RTI

Finally, while almost half of respondents selfidentified to be entered into the Visa gift card drawing, less than ten percent of self-identified to be contacted to discuss mental health RTI. Follow-up interviews and case studies are currently underway.

\section{Discussion}

As many as $80 \%$ of youth in US schools who have moderate to severe mental health needs receive no treatment. The short- and longterm consequences of untreated and unmonitored mental health problems that begin in childhood and adolescence are dire and well- 
documented. Legislative and educational initiatives at both the national and state levels conceptual frameworks for prioritizing student mental health outcomes within school settings but lack research-based guidelines to implement and evaluate interventions or monitor mental health progress. Similarly, though Response to Intervention (RTI) is a promising broad conceptual model of providing continuum of effective interventions for a wide variety of academic and social, emotional and behavioral concerns in school, the research and dialog around RTI has been quite narrow, with the vast majority focusing on academics. Unlike the plethora of instruction to create and enact an academic-RTI, the literature on RTI for mental health is scant, generally focusing on the need for universal screening and providing only general principles and suggested elements schools and districts.

Seemingly unique in its focus and scope, this study sought to begin to address the literature gap around best practice guidelines and procedures to provide tiered systems of school-based supports to meet the mental health needs of children and adolescents by first identifying current practices, as well as, perceived enhancers and inhibitors.

Preliminary results of a state-wide survey of 174 school psychologists employed in public or private schools found that only $16 \%$ of schools engaged in universal mental health screening two or more times annually. Though slightly higher than a recent estimate of national screening practices by Bruhn and colleagues [17], the implication is that over $80 \%$ of Massachusetts schools do no form of systematic mental health screening. Though different in specifics (e.g., frequency), generally, similarities to national trends were found. For example, most school-based screening used comprehensive, publish rating scales. The remainder used tools screening tools that are available for free or at low cost and have a narrower foci on depression and/or suicide risk. Similarly, disciplinary referrals and attendance were other data used to identify students at-risk for mental health concerns. Different from national trends, some Massachusetts schools also consider academic achievement difficulties/poor/lowered grades and visits to the nurse relative to potential mental health concerns.

Half of respondents reported that data regarding risk or documented mental health concerns was not systematically gathered or maintained for students in general education (i.e., who did not services or accommodations for mental health concerns via IEPs or 504 plans). For the half that reporting some form of data collection, the process varied from paper notebooks and personal counseling notes to limited access laptops, tablets and cloud-based data storage. In terms of title or role, the mental health personnel responsible for data collection and monitoring varied widely across schools.

The availability of monetary-reliant or human-provided resources to support students was identified as the number one factor which could facilitate or inhibit mental health RTI in Massachusetts schools. Second was communication patterns among school-based personnel. These were consistent with national and state policy recommendation and frameworks to develop safe and supportive schools. Varied training and expertise among school-based personnel and leadership patterns rounded out the list of identified drivers and barriers.

These preliminary findings are somewhat encouraging in that schools not only recognize the need for but are taking steps to establish mental health RTI and can identify local facilitators and barriers to that process. That said, these results underscore the sobering fact that we have a long way to go.

The logical first step in the next phase of determining best practices in providing mental health RTI seems to be further exploration of current practices. This would begin with identifying how the progress of students receiving services and accommodations for mental health concerns through 504 and IEPs is monitored due to the mandatory nature of the monitoring. This would include identifying the data, and how it is collected, analyzed, recorded, reported and communicated across time and setting.

Given the potential for yet to be discovered options, the recommended second step is to determine how the different mental health risk factors are recorded, monitored and communicated across time and setting. Third, case studies of settings that are planning for or enacting complete or partial RTI models is recommended to identify processes and their potential generalizability. Finally, given the great potential value to a multitude of schoolsettings, it is recommended that these case studies inquiry into strategies to leverage and increase facilitators, as well as decrease and circumvent barriers to their local mental health RTI models. 


\section{Limitations}

Sample size and characteristics likely limit the generalizability of some but not all current and potential future findings. The sample size was small and comprised of members of only one profession in one state. Early and very early career professionals were overrepresented. Target schools were less ethnically and racially diverse than those across the state. Elementary schools were overrepresented.

\section{Acknowledgement}

This study was made possible in part by a Faculty Mini-Grant awarded by the Academic Affairs Division of Worcester State University, Worcester, Massachusetts, United States of America.

\section{References}

[1] National Alliance of Mental Illness (NAMI, 2013). Mental illness facts and numbers. Retrieved from: http://www2.nami.org/ factsheets/mentalillness_factsheet.pdf

[2] Centers for Disease Control and Prevention. (2013) Mental Health Surveillance among Children-United States 2005-2011. MMWR 2013;62 (Suppl. May 16, 2013):1-35. Retrieved from: https://www.cdc.gov/mmwr/preview/ mmwrhtml/su6202a1.htm

[3] Glowinski, A.L. \& D'Amelio, D. (2016). Depression Is a Deadly Growing Threat to Our Youth: Time to Rally. Pediatrics 138(6). http://pediatrics.aappublications.org/content/pedi atrics/early/2016/11/10/peds.2016-2869.full.pdf

[4] National Association of School Psychologists (NASP, 2015). School psychologists: Qualified health professionals providing child and adolescent mental and behavioral health services. Communique, 44(1), $1,24-25$.

[5] Cheung, A.H., Dewa, C.S., Cairney, J., Veldhuizen, S., \& Schaffer, A. 2009. Factors associated with use of mental health services for depressed and/or suicidal youth. Journal of Community Mental Health, 45, 300-306.

[6] Clemens, E.V., Welfare, L.E. \& Williams, A.M. (2011). Elements of successful school reentry after psychiatric hospitalization.
Preventing School Failure, 55(4), 202-213. DOI: 10.1080/1045988X.2010.532521

[7] Massachusetts Department of Elementary and Secondary Education (2011). Massachusetts Tiered System of Supports. http://www.doe.mass.edu/ sped/mtss.html

[8] Behavioral Health and Public Schools Task Force (2011). Creating safe, healthy, and supportive learning environments to increase success for all students: Final Report. Malden, MA: Author.

[9] Cowan, K.C., Vaillancourt, K., Rossen, E., \& Pollitt, K. (2013). A Framework for Safe and Supportive Schools [Brief]. Bethesda, MD: National Association of School Psychologists.

[10] Sugai, G. \& Horner, R.H. (2009). Responsiveness-to-intervention and school-wide positive behavior supports: Integration of multitiered system approaches. Exceptionality, 17(4), 223-237.

[11] Edmonds, R.Z. (2017) Ask the Experts: MTSS and RTI are often used interchangeably: What is it that separates them? Washington, DC: Center on Response to Intervention at the American Institutes of Research.

[11] RTI Action Network (2017). What is RTI? New York: National Center for LD. http://www.rtinetwork.org/learn/what/whatisrti

[13] Castillo, J.M. (2014). Best practices in program evaluation in a model of response to intervention/multi-tiered system of supports. In P.L. Harrison \& A. Thomas (Eds.), Best practices in school psychology: System-level services.

[14] VanDerHeyden A.M., Witt J.C., \& Barnett D.W. (2005). The emergence and possible futures of response to intervention. Journal of Psychoeducational Assessment. 23:339-361.

[15] Barnes, A.C., \& Harlacher, J.E. (2008). Clearing the confusion: Response-tointervention as a set of principles. Education and Treatment of Children, 31, 417-431.

[16] Fuchs, D., \& Fuchs, L.S. (2006). Introduction to responsiveness to intervention: What, why and how valid is it? Reading Research Quarterly, 41, 92-99. DOI: 10.1598/RRQ.41.1.4 
[17] Bruhn, A.L., Woods-Groves, S., \& Huddle, S. (2014). A preliminary investigation of emotional and behavioral screening practices in K-12 schools. Education and Treatment of Children, 37(4), 611-634. DOI: 10.1353/etc.2014.0039

[18] Burns, M.K., Riley-Tilman, T.C., \& VanDerHeyden, A.M. (2012). RTI Applications Volume 1: Academic and Behavioral Interventions. New York: Guilford.

[19] Stormont, M., Reinke, W.M., Herman, K.C. \& Lembke, E.S. (2012). Academic and Behavior Supports for At-Risk Students: Tier 2 Interventions. New York: Guilford.

[20] Willis, J. (2017, September 7). Question on MTSS/RTI data. [Electronic mailing list message] http://groups.yahoo.com/group/School -Psychology-Listserv

[21] Levy, B. (2017, August 9). Record Keeping. [Electronic mailing list message] http://groups.yahoo.com/group/School-Psychology-Listserv

[22] Massachusetts Department of Elementary and Secondary Education (2005). Education Laws and Regulations. Student records: Questions, answers and guidelines. Retrieved from http://www.doe.mass.edu/lawsregs/ advisory/cmr23qanda.html? section=other

[23] National Research Council and Institute of Medicine. (2009). Preventing mental, emotional, and behavioral disorders among young people: Progress and possibilities. Washington, DC: The National Academies Press. http://dhss.alaska.gov/dbh/Documents/Prevention/programs/spf sig/pdfs/IOM_Matrix_8\%205x11_FINAL.pdf 